\title{
Outcome reporting in laryngotracheal surgery: we need functional analysis!
}

\author{
Thomas Schweiger, Konrad Hoetzenecker, Walter Klepetko \\ Department of Surgery, Division of Thoracic Surgery, Medical University of Vienna, Vienna, Austria \\ Correspondence to: Prof. Walter Klepetko, MD. Division of Thoracic Surgery, Medical University of Vienna, Waehringer Guertel 18-20, A-1090 \\ Vienna, Austria. Email: walter.klepetko@meduniwien.ac.at.
}

Submitted Feb 01, 2020. Accepted for publication Feb 27, 2020.

doi: $10.21037 /$ tcr.2020.02.18

View this article at: http://dx.doi.org/10.21037/tcr.2020.02.18

The review article "Functional evaluation before and after laryngo-tracheal resection" as contained in this special issue provides key variables of a structured functional assessment in laryngotracheal surgery (1). Based on the low number of patients suffering from laryngotracheal stenosis, most published series on treatment outcomes comprise less than 50 patients (2). In addition, outcome reporting is restricted to only surgical parameters (such as length of stay, rate of dehiscence, decannulation rates) in many publications. We believe that reporting functional outcomes for surgical procedures in such a delicate area as the laryngotracheal junction should be mandatory. The definition and standardized reporting of functional parameters are essential for the further development of laryngotracheal surgery.

In the first place, the longitudinal, functional assessment of patients receiving laryngotracheal surgery provides a deeper understanding of the anatomical and functional changes after surgical procedures. Despite recent innovations in surgical and endoscopic techniques, the existing literature on pre- and postoperative voice quality is still sparse $(3,4)$. The structured functional evaluation may elucidate the impact of these specific surgical techniques on the postoperative laryngeal functioning.

Moreover, a standardized reporting of functional variables provides the basis for comparing different treatment strategies. Beyond the stratification of patient cohorts depending on the type of procedure, the preoperative functional impairments have to be reported and considered during the interpretation of data. Lastly, a standardized functional assessment will enable the scientific community to combine and compare data from different centers. In order to conduct scientifically meaningful studies in laryngotracheal surgery, the contribution of major centers to databases and multicenter trials is of paramount importance. The foundation of the North American Airway Collaborative (NoAAC) and the AIR database by the Brazilian Society of Thoracic Surgeons and the European Society of Thoracic Surgeons are recent examples of international efforts acquiring meaningful datasets from multiple international institutions (5).

Beyond additional functional measures, the value of the self-perceived outcome reporting by patients should be emphasized (Figure 1). Questionnaires on the quality of life before and after treatment are valuable tools and should be incorporated into scientific publications as they provide a patient-centered evaluation of the treatment success in a standardized manner.

In summary, a standardized collection and reporting of functional outcome variables is important to refine surgical techniques and to improve the treatment quality of patients with laryngotracheal pathologies.

\section{Acknowledgments}

Funding: None.

\section{Footnote}

Provenance and Peer Review: This article was commissioned by the editorial office, Translational Cancer Research for the series "Recent Developments in Benign Tracheal Stenosis". The article did not undergo external peer review.

Conflicts of Interest: All authors have completed the ICMJE uniform disclosure form (available at http:// dx.doi.org/10.21037/tcr.2020.02.18). The series "Recent 


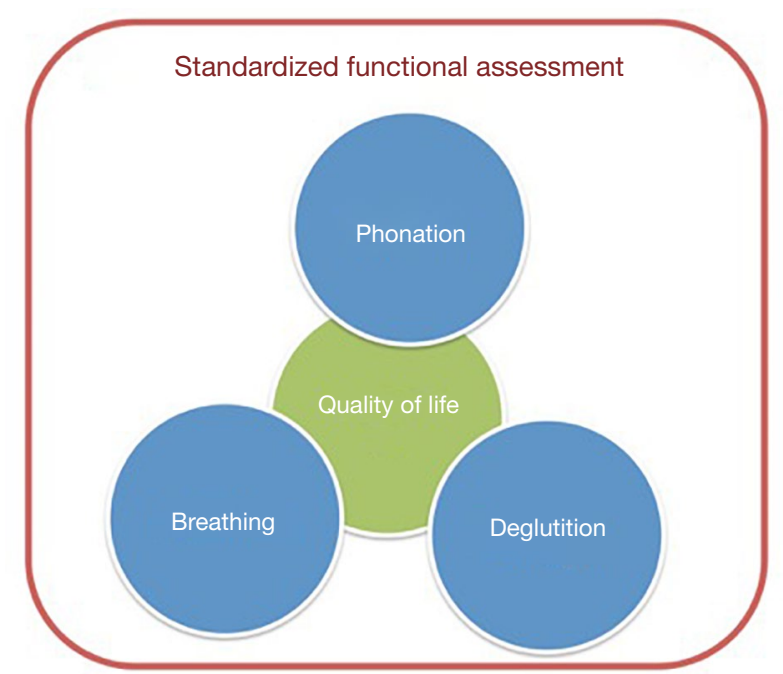

Figure 1 The standardized assessment and reporting of functional measures including self-reporting of patients' quality of life are a prerequisite for the further development of laryngotracheal surgery.

Developments in Benign Tracheal Stenosis" was commissioned by the editorial office without any funding or sponsorship. KH served as the unpaid Guest Editor of the series. The authors have no other conflicts of interest to declare.

Ethical Statement: The authors are accountable for all aspects of the work in ensuring that questions related to the accuracy or integrity of any part of the work are appropriately investigated and resolved.

Open Access Statement: This is an Open Access article distributed in accordance with the Creative Commons Attribution-NonCommercial-NoDerivs 4.0 International License (CC BY-NC-ND 4.0), which permits the noncommercial replication and distribution of the article with the strict proviso that no changes or edits are made and the original work is properly cited (including links to both the formal publication through the relevant DOI and the license). See: https://creativecommons.org/licenses/by-nc-nd/4.0/.

Cite this article as: Schweiger T, Hoetzenecker K, Klepetko W. Outcome reporting in laryngotracheal surgery: we need functional analysis! Transl Cancer Res 2020;9(3):2097-2098. doi: $10.21037 /$ tcr.2020.02.18

\section{References}

1. Rahimi N, Roesner I, Schweiger T, et al. Functional evaluation before and after laryngo-tracheal resection. Transl Cancer Res 2020;9:2142-8.

2. Yamamoto K, Kojima F, Tomiyama K, et al. Meta-analysis of therapeutic procedures for acquired subglottic stenosis in adults. Ann Thorac Surg 2011;91:1747-53.

3. Tanner K, Dromey C, Berardi ML, et al. Effects of voicesparing cricotracheal resection on phonation in women. Laryngoscope 2017;127:2085-92.

4. Hoetzenecker K, Schweiger T, Roesner I, et al. A modified technique of laryngotracheal reconstruction without the need for prolonged postoperative stenting. J Thorac Cardiovasc Surg 2016;152:1008-17.

5. Daniero JJ, Ekbom DC, Gelbard A, et al. Inaugural Symposium on Advanced Surgical Techniques in Adult Airway Reconstruction: Proceedings of the North American Airway Collaborative (NoAAC). JAMA Otolaryngol Head Neck Surg 2017;143:609-13. 